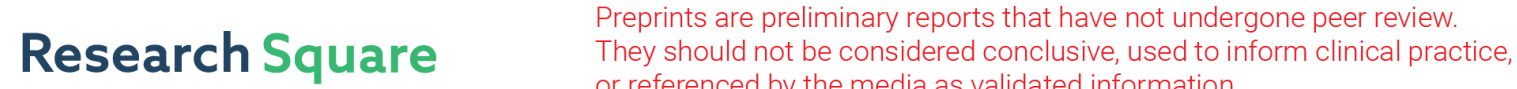 or referenced by the media as validated information. \\ Modeling and Simulation of Knowledge Innovation Diffusion in Weighted Scale-free Industry-University- Research Cooperative Innovation Network
}

\author{
Xia Cao \\ Harbin Engineering University \\ Chuanyun Li ( $\square$ lichuanyun123@126.com ) \\ Harbin Engineering University \\ Jinqiu Li \\ Harbin Engineering University \\ Yunchang Li \\ Harbin Engineering University
}

\section{Research Article}

Keywords: BBV model, object, abruptly, hub institutions

Posted Date: November 25th, 2020

DOI: https://doi.org/10.21203/rs.3.rs-107986/v1

License: (c) (i) This work is licensed under a Creative Commons Attribution 4.0 International License.

Read Full License 


\title{
Modeling and Simulation of Knowledge Innovation Diffusion in Weighted Scale-free Industry-University-Research Cooperative Innovation Network ${ }^{1}$
}

\begin{abstract}
Xia Cao, Chuanyun Li, Jinqiu Li, Yunchang Li
School of Economics and Management, Harbin Engineering University, Harbin 150001, China

Abstract: With the weighted scale-free cooperative innovation network of industry-university-research established by the weighted evolutionary BBV model as the research object, based on the interaction between knowledge innovation diffusion and network structure, a corresponding model of knowledge innovation diffusion is constructed. By using complex network theory and simulation analysis methods, the evolution law of knowledge innovation diffusion in the industry-university-research cooperative innovation network is analyzed. The results show that the overall knowledge level of the industry-university-research cooperative innovation network shows a rapid growth trend, and the growth rate of knowledge shows a changing trend of slowing first and then increasing abruptly; the greater the degree of the innovator, the higher its knowledge level; the more stable the cooperative relationships between innovator, and the stronger its knowledge diffusion ability; the knowledge diffusion mode and network structure are the reasons for the emergence of sudden changes in the network; the knowledge diffusion constraints and network structure are the keys to knowledge innovation and diffusion; with the passage of time, the knowledge level differentiation among innovators gradually increases, and the role of hub institutions in knowledge innovation diffusion becomes increasingly prominent.
\end{abstract}

\section{Introduction}

As an important part of national innovation systems, industry-university-research cooperative innovation network are an important platform for realizing knowledge innovation diffusion ${ }^{[1,2]}$. The evolution of the knowledge innovation diffusion behavior of innovators is the motivation of network evolution, and the evolution of the network structure is the key factor influencing the knowledge innovation diffusion behavior of innovators ${ }^{[3]}$. Existing research finds that in the evolution process of industry-university-research cooperative innovation network, the process of knowledge innovation diffusion is not only affected by potential differences in knowledge and network topology ${ }^{[4]}$ but is also closely related to the strength of cooperation between innovators ${ }^{[5]}$ and has the characteristics of weighted scale-free networks ${ }^{[6]}$. However, a simulation network based on the weighted evolution BBV model can simulate the real networks very well ${ }^{[7]}$. Therefore, this paper takes the weighted scale-free industry-university-research cooperative innovation network as the research object, considering the interaction between knowledge innovation diffusion and network structure and revealing the evolution law of knowledge innovation diffusion in the network. The research is of great significance to promoting the evolution and development of industry-university-research cooperative innovation network.

With the rapid development of network science, research on knowledge innovation diffusion in networks has attracted extensive attention ${ }^{[8]}$. Some scholars based their work on the perspective of influencing factors to study the influence of knowledge diffusion in a network. For example, the regression analyses of Xie et al. ${ }^{[9]}$ and Darvish ${ }^{[10]}$ found that network structure indexes such as network scale and connection strength have a positive impact on knowledge diffusion. Chen et al. ${ }^{[11]}$, Mao et al. ${ }^{[12]}$ and

\footnotetext{
1"*Correspondence to [lichuanyun123@126.com]"
} 
Havakhor et al. ${ }^{[13]}$ conducted simulation analyses and found that the main ability, spatial relevance and knowledge role distribution of a network have an important impact on the knowledge diffusion process. Some scholars only consider the process of knowledge diffusion, build the corresponding knowledge diffusion model, and study the evolution law of knowledge diffusion under the given static network structure. For example, Cowan ${ }^{[14]}$, Wang et al. ${ }^{[15]}$ and Zheng et al. ${ }^{[16]}$ built a knowledge diffusion model based on the barter exchange perspective, social network perspective and knowledge dissemination perspective respectively, and simulated and analyzed the evolution of knowledge diffusion under rule network, small-world network, scale-free network and other static topological structures. Some scholars consider knowledge innovation and knowledge diffusion synthetically, build the corresponding model of knowledge innovation diffusion, and explore the evolution law of knowledge diffusion under the given static network structure. For example, Huang et al. ${ }^{[17]}$, Chen et al. ${ }^{[18]}$ and Zhang et al. ${ }^{[19]}$ considered factors such as cooperation distance, knowledge transfer willingness and knowledge type, constructed a knowledge innovation diffusion model, and simulated and analyzed knowledge diffusion rules under static topological such as rule network, small-world network and scale-free network. Yu et al. ${ }^{[20]}$ considered the factors such as knowledge absorption capacity, knowledge diffusion willingness and knowledge spillover efficiency, built a multiagent technology innovation network knowledge growth model, and analyzed the impact of network density on knowledge growth. Then, some scholars explored the evolution of knowledge diffusion under the interactions between the network structure, knowledge creation, and knowledge diffusion. For example, Luo et al. ${ }^{[1]}$ considered factors such as knowledge distance and knowledge exchange efficiency to construct a coevolution model for network structure and knowledge diffusion and explored the evolution law of knowledge diffusion under random networks and small-world networks. Tur et al. ${ }^{[22]}$ considered the cost of cooperation, the number of cooperation, and the time scale to construct a coevolution model for network structure and knowledge innovation and simulated and analyzed the evolution law of the knowledge level of innovators in small-world networks under different feedback processes.

Looking at the existing research, we find that the research on knowledge innovation diffusion in a network has been performed on a large scale, but there are still three deficiencies as follows: (1) In the existing research, the models of knowledge innovation diffusion are relatively simplified, and the influencing factors covered by the diffusion functions are not comprehensive, ignoring the impact of the strength of cooperation between innovators and the heterogeneity of innovators on the diffusion of knowledge innovation. (2) Most scholars take rule networks, small-world networks and BA scale-free networks as the network models, and relevant research under weighted networks is lacking. (3) Most of the existing studies analyze the evolution rule for knowledge diffusion under a given static network or only analyze the knowledge diffusion rule under the interactions of knowledge innovation, knowledge diffusion and network structure. These studies lack the combination of knowledge innovation and the knowledge diffusion process and analyze the knowledge diffusion rule under the interaction of knowledge innovation diffusion and network structure. In view of this, based on the interaction between the network structure and knowledge innovation diffusion, this paper constructs the corresponding diffusion model of knowledge innovation using complex network theory and simulation analysis methods and analyzes the evolution law of knowledge innovation diffusion in an industry-university-research cooperative innovation network. This research has important theoretical significance and can be a practical reference for promoting the evolution and development of industry-university-research cooperative innovation network. 


\section{Interactive process analysis of the network structure of industrial university research cooperative innovation and knowledge innovation diffusion}

Due to the interaction between the network structure and knowledge innovation diffusion, there are complex interactions between the network structure and the behavior of the innovators. Therefore, the process of knowledge innovation and diffusion in an industry-university-research cooperative innovation network can be regarded as a special case of an "adaptive coevolution network" ${ }^{\text {"[21] }}$. Based on reference ${ }^{[23]}$, this paper improves the analysis framework of the interaction process between the network structure of industry-university-research cooperative innovation and knowledge innovation diffusion, as shown in Fig. 1. The square and the circle represent the enterprise and the university-research institution, respectively. In the process of knowledge innovation diffusion, due to the different scales of innovators, R\&D innovation ability, absorption ability, and knowledge diffusion conditions in the industry-university-research cooperative innovation network ${ }^{[24]}$, the knowledge levels among innovators are quite different, to realize the overall diffusion of knowledge in the network. In the pursuit of the maximization of their knowledge benefits, the innovators will adjust their cooperation behavior according to the changes in the knowledge potential difference between them. Additionally, due to the limited rationality of innovators, they will adjust their cooperation objects through the reconnection mechanism by connection preference ${ }^{[25]}$ and then change the topological structure of the industry-university-research cooperative innovation network. However, the change in the topological structure of the industry-university-research cooperative innovation network has changed the cooperative relationship between the innovators, so that during the process of knowledge innovation diffusion, the knowledge income of the innovator changes, which affects the knowledge potential difference between the innovators, changes the selection of the cooperation strategies of the innovators, and then affects the process of knowledge innovation diffusion in the weighted industry-university-research cooperative innovation network.

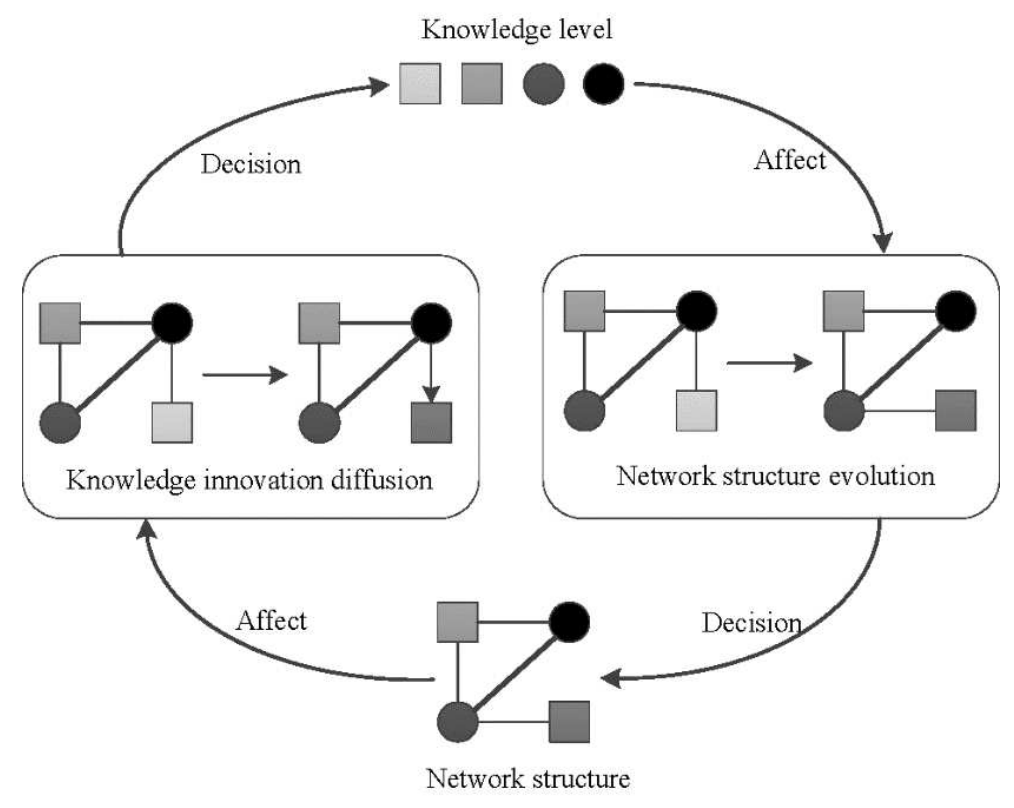

Figure 1. Analysis framework of interaction process between industry-university-research cooperative innovation network structure and knowledge innovation diffusion

\section{Knowledge innovation diffusion model construction and index measurement}

\section{Diffusion model of knowledge innovation}

In the process of knowledge innovation diffusion, the knowledge growth of innovators in the 
industry-university-research cooperative innovation network comes from three parts: the knowledge obtained by innovators in $R \& D$ and creation, the knowledge obtained and absorbed by using the cooperative innovation relationship between innovators and the knowledge obtained from outside of the network. The knowledge growth of innovators in the industry-university-research cooperative innovation network mainly comes from the inside of the network ${ }^{[17]}$. Therefore, in the process of constructing the model of knowledge innovation diffusion, this paper only considers the first two sources of knowledge growth.

In the process of knowledge innovation diffusion, the industry-university-research cooperative innovation network is mainly affected by the innovator capacity, knowledge diffusion conditions and network structure ${ }^{[26,27]}$. An innovator's ability includes the innovator's R\&D innovation ability and the innovator's ability to understand, digest and accept the acquired knowledge through direct or indirect diffusion $^{[28]}$. The knowledge diffusion conditions include the willingness of knowledge senders to transfer their knowledge to knowledge receivers and the efficiency of innovators in acquiring knowledge through direct or indirect diffusion, that is, knowledge spillover efficiency ${ }^{[29]}$. The network structure includes the cooperation distance between innovators and the close degree of cooperation between innovators, that is, the strength of cooperative relationships ${ }^{[30]}$.

Suppose that in the $t$ period, the knowledge stock of the innovator is $s_{i}(t), i=1,2, \mathrm{~L}, N$. In the process of knowledge innovation diffusion, the knowledge growth of innovators in the industry-university-research cooperative innovation network evolve in the following ways.

(1) Knowledge innovation process

In period $t$, if innovator $i$ in the industry-university-research cooperative innovation network completes $\mathrm{R} \& \mathrm{D}$, then in period $(t+1)$, the knowledge growth of the innovator is as follows:

$$
s_{i}(t+1)=\left(1+\alpha_{i}\right) s_{i}(t)
$$

Among them, $\alpha_{i}$ is the R\&D innovation capability coefficient of innovator $i$.

(2) Knowledge diffusion process

In the process of knowledge diffusion, the knowledge receiver first understands the knowledge resources that the knowledge sender is willing to spread and identifies the knowledge valuable to itself. Then, under the influence of innovator ability, knowledge diffusion conditions and network structure, the knowledge sender diffuses knowledge in the network directly or indirectly. Among them, the direct diffusion of knowledge is affected by the strength of cooperation between innovators and the efficiency of knowledge spillover. The indirect diffusion of knowledge is affected by the distance of cooperation between the innovators and the efficiency of the knowledge spillover. Finally, the knowledge receiver digests and absorbs the acquired knowledge resources by the receiver's own absorption ability and internalizes the acquired knowledge into its own knowledge. Therefore, in the $(t+1)$ period, the knowledge levels of the innovators change through direct knowledge diffusion as follows:

$$
s_{j}(t+1)=\left\{\begin{aligned}
& s_{j}(t)+\delta_{1}^{d_{i j}}\left(1-e^{-\left(w_{i j}+\gamma_{j}\right)}\right)\left[\beta_{i} s_{i}(t+1)-s_{j}(t)\right] \\
& \text { if } \beta_{i} s_{i}(t+1)>s_{j}(t), \text { and } d_{i j}=1 \\
& s_{j}(t) \text { if } \beta_{i} s_{i}(t+1) \leq s_{j}(t), \text { or } d_{i j} \neq \infty
\end{aligned}\right.
$$

In the $(t+1)$ period, the knowledge level of innovator $j$ changes through indirect knowledge diffusion as follows: 


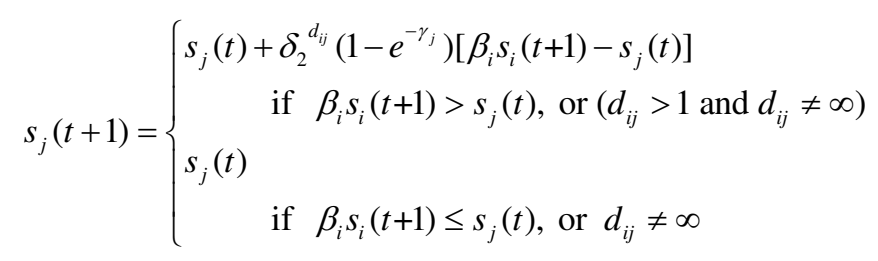

Among them, $\delta_{1}$ and $\delta_{2}$ are the knowledge spillover efficiency of direct diffusion and indirect diffusion respectively, where $0 \leq \delta_{1}, \delta_{2} \leq 1 . d_{i j}$ is the cooperation distance between nodes $i$ and $j$, $\beta_{i}$ is the knowledge transfer intention of node $i$, and $\gamma_{i}$ is the knowledge absorption ability of node $j$. $w_{i j}$ indicates the strength of the cooperative relationship between nodes $i$ and $j$ with a direct cooperative innovation relationship. When there is no direct cooperative innovation relationship between innovators $i$ and $j$, the strength of the cooperative relationship is $w_{i j}=0$. In the $(t+1)$ period, if there is a direct cooperative relationship $\left(d_{i j}=1\right)$ between node $i$ and node $j$ and the knowledge level $\beta_{i} s_{i}(t+1)$ that node $i$ is willing to spread is higher than the knowledge level $s_{j}(t)$ of node $j$, then direct knowledge diffusion is carried out. If there is an indirect cooperative relationship $\left(d_{i j}>1\right.$ and $\left.d_{i j} \neq \infty\right)$ between node $i$ and node $j$ and the knowledge level $\beta_{i} s_{i}(t+1)$ that node $i$ is willing to spread is higher than the knowledge level $s_{j}(t)$ of node $j$, then indirect knowledge diffusion is carried out. If there is no knowledge diffusion path $\left(d_{i j} \neq \infty\right)$ between node $i$ and node $j$ or the knowledge level $\beta_{i} s_{i}(t+1)$ that node $i$ is willing to spread is lower than the knowledge level $s_{j}(t)$ of node $j$, then there is no knowledge diffusion between them.

\section{Measurement of knowledge innovation diffusion performance}

Due to the two-way influence of the topological structure and the knowledge innovation diffusion of the industry-university-research cooperative innovation network, the knowledge levels of the innovators are constantly improving, and the overall diffusion of knowledge in the network is realized ${ }^{[19]}$, so that the performance of knowledge innovation diffusion in the industry-university-research cooperative innovation network is constantly changing. Based on the idea of literature ${ }^{[17,18]}$, this paper studies the performance of knowledge innovation diffusion in the industry-university-research cooperative innovation network from four aspects: the overall knowledge level of the network, the uniformity of the knowledge level distribution, the spatial distribution of the knowledge level and the dynamic evolution of the individual knowledge level.

The overall knowledge level of the network $S(t)$ refers to the average knowledge level of the innovators in the period $t$, which measures the overall knowledge stock of the network:

$$
S(t)=\frac{1}{n} \sum_{i=1}^{n} s_{i}(t)
$$

The knowledge growth rate $V(t)$ reflects the change in the knowledge level increment in the 
industry-university-research cooperative innovation network.

$$
V(t)=\frac{S(t)}{S(t-1)}-1
$$

The uniformity of the knowledge level distribution $C(t)$, which represents the ratio between the standard deviation of the innovator's knowledge level and the overall knowledge level of the network in period $t$, which measures the efficiency of knowledge resource allocation in the network.

$$
C(t)=\frac{\sigma(t)}{S(t)}
$$

Among them, $\sigma(t)$ refers to the standard deviation of the knowledge level of the innovators in the period $t$. The larger the standard deviation of the knowledge level is, the more uneven the distribution of the knowledge level is, and the more obvious the degree of knowledge level differentiation is.

The spatial distribution of knowledge level $M(t)$ refers to the relationship between the knowledge level of the innovators in the network and their spatial locations in the period of $t$, which measures the similarity of the knowledge levels among the innovators gathered in a spatial location, generally measured by the Moran coefficient ${ }^{[31]}$.

$$
\begin{gathered}
M(t)=\frac{1}{\sigma^{2}(t)} \sum_{i=1}^{N} \sum_{j \neq i}^{N} w_{i j}\left[s_{i}(t)-S(t)\right]\left[s_{j}(t)-S(t)\right] \\
w_{i j}=\frac{X(i, j)}{\sum_{i=1}^{N} \sum_{j \neq i}^{N} X(i, j)}
\end{gathered}
$$

Among them, $X$ is the adjacency matrix of the spatial weight, and the value of $X(i, j)$ reflects the closeness of the cooperative innovation relationship between innovators $i$ and $j$. If there is no cooperative innovation relationship between innovator $i$ and $j, X(i, j)$ is equal to $0 . M(t) \in[-1,1]$; if $M(t): 0 \quad$, it means that the spatial distribution of the knowledge level in the network is random, and there is no spatial agglomeration. If $M(t)>0$, it means that the innovators with similar knowledge levels tend to generate spatially agglomerate. If $M(t)<0$, it means that the innovators with different knowledge levels in the network tend to generate spatially agglomerate.

The dynamic evolution of the individual knowledge levels reflect the changes in the knowledge levels of all the innovators in the industry-university-research cooperative innovation network in different periods.

\section{Basic assumptions and network evolution rules}

\section{Basic assumptions}

On the basis of determining the industry-university-research cooperative innovation network established by the BBV model of empowerment evolution as the carrier of knowledge innovation diffusion. At the same time, considering the characteristics of the industry-university-research cooperative innovation network and the reality of the process of knowledge innovation diffusion, this paper puts forward the following assumptions:

Hypothesis 1: In the industry-university-research cooperative innovation network, enterprises and university-research institutions are heterogeneous innovators, and the R\&D innovation ability, absorptive capacity transfer willingness and knowledge spillover efficiency of each innovator are different.

Hypothesis 2: In the evolution process of the industry-university-research cooperative innovation network, the network structure is only adjusted according to the rule of disconnection and reconnection, and the influences on the network structure are not considered under the conditions of node and connection growth. 
Hypothesis 3: The innovator is a limited rational individual and can only choose diffusion or nonproliferation.

\section{Network evolution rules}

In the period $t$, if there is no knowledge diffusion between node $i$ and neighbor node $j$ in the industry-university-research cooperative innovation network, that is, $\beta_{i} s_{i}(t+1)<s_{j}(t)$, then in the next round of the knowledge innovation diffusion process, node $j$ disconnects and reconnects with other nodes in the network with probability $\Upsilon_{j m}(t+1)$. Considering that the innovators are all limited rational individuals and have certain preferences in partner selection, this paper uses the mechanism of reconnection with connection preference ${ }^{[25]}$ to determine the outgoing connection $m$ of node $j$, and the random probability is:

$$
\Upsilon_{j m}(t+1)=\sum_{j \in G_{T}} \frac{s_{m}^{K}(t)}{s_{j}^{K}(t)}
$$

Among them, $s_{m}$ is the knowledge level of innovator $m$ in the period $t$, and $G_{T}$ represents the collection of innovator $j$. When $T=1, G_{1}$ represents the collection of enterprises, and when $T=2$, $G_{2}$ represents the collection of university-research institutions. $K$ indicates preference tendency; $K=0$ indicates no preference connection tendency, i.e., random connection. On the contrary, the preference is more obvious. In this paper, a high preference of $K=1$ is selected for simulation.

\section{Simulation analysis}

\section{Simulation parameter settings}

To reflect the different characteristics of the innovation ability of enterprises and university-research institutions in the industry-university-research cooperative innovation network. We believe that the main body of knowledge, university-research institutions have a higher ability of knowledge innovation in the process of knowledge innovation. In addition, This paper set categorizes them into two types: advantage and general. If the degree value of an enterprise or university-research institution is greater than 4 , it is regarded as an advantage innovator; otherwise, it is regarded as a general innovator. At the initial moment $(t=0)$, the knowledge level, knowledge transfer willingness, absorption ability and knowledge innovation ability of advantage enterprises and advantage university-research institutions are subject to a uniform distribution of $(0.5,1)$, and the knowledge level, knowledge transfer willingness, absorption ability and knowledge innovation ability of general enterprises and general university-research institutions are subject to a uniform distribution of $(0,0.5)$. Based on reference [18], we set the direct spillover efficiency as $\delta_{1}=0.5$ and the indirect knowledge spillover efficiency as $\delta_{2}=0.2$. In this paper, MATLAB $2017 \mathrm{~b}$ software is used for simulation analysis. The total number of nodes in the industry-university-research cooperative innovation network is 200, among which 50\% are enterprises and 50\% are university-research institutions, and these innovators are evenly distributed in the network. The number of simulation times is 1000 , and the average value is obtained by simulating the same set of parameters 30 times.

\section{Changes in the overall knowledge level of the network}

In the process of knowledge innovation diffusion, the knowledge level of the innovators in the industry-university-research cooperative innovation network gradually improves, and the performance of the knowledge innovation diffusion also changes. Fig. 1 shows the change in the overall knowledge level of the network, reflecting the evolution law of the average knowledge level in the 
industry-university-research cooperative innovation network. Fig. 2 shows the change in the knowledge growth rate, reflecting the evolution law of the knowledge growth performance in each period.

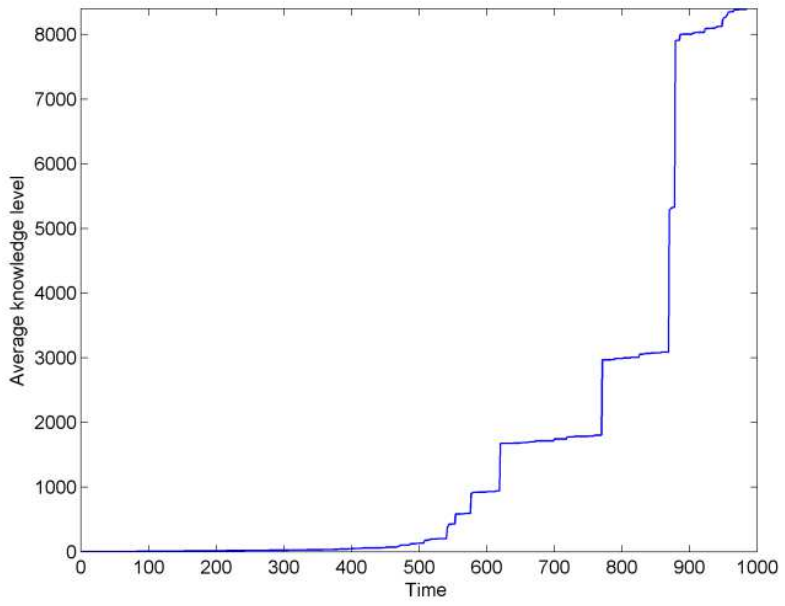

Figure 2. Changes in the overall knowledge level

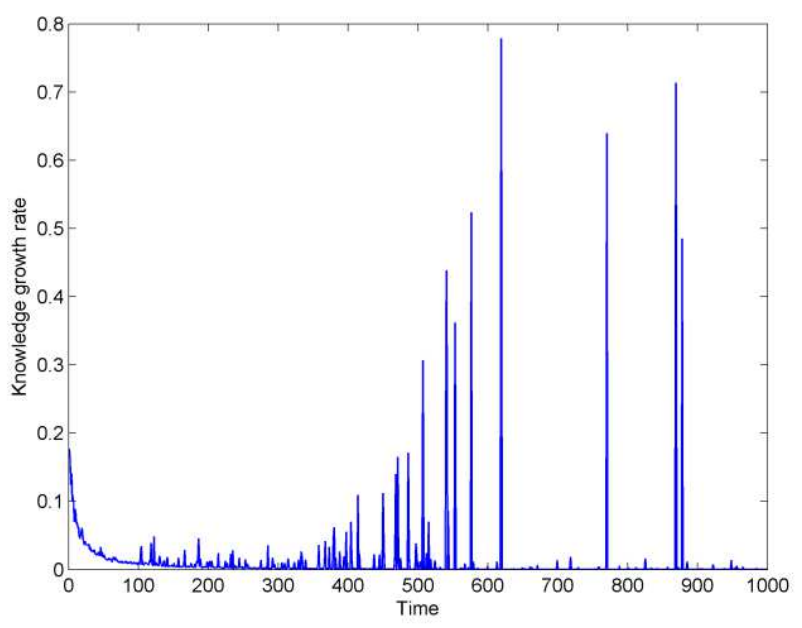

Figure 3. Change in the knowledge growth rate of the network

Fig. 2 and Fig. 3 show that the overall knowledge level of the industry-university-research cooperative innovation network shows a trend of slow growth first and then sudden growth, while the growth rate of knowledge shows a trend of decreasing first, then suddenly growing, and finally becoming stable. In the early stage of evolution $(t<300)$, the overall knowledge level of the network shows a slow-growth trend, while the growth rate of knowledge gradually decreases. This occurs because in the early stage of evolution, due to the interaction between the network structure and the knowledge innovation diffusion, the network structure of the industry-university-research cooperative innovation network changes, the distance of cooperation between innovators gradually increases, and the network connectivity weakens, so that the scope of the knowledge diffusion among innovators gradually declines. Finally, the growth rate of knowledge gradually declines, the overall knowledge of the network gradually declines, and the level shows a slow growth trend. In the middle of the evolution $(300<t<600)$, because the network structure of the industry-university-research cooperative innovation network has changed greatly, the scope of the knowledge diffusion among innovators is relatively small, and the influence of general innovators on the overall knowledge level of the network gradually weakens. However, the advantage innovators have a relatively large number of cooperative neighbors and a relatively strong cooperative relationship with other innovators, which can achieve knowledge diffusion in the network to a great extent, so that the overall level of knowledge of the network shows a sudden increase, and the knowledge growth speed increases continuously under the sudden change. In the late stage of evolution $(600<t<1000)$, the overall knowledge level of the network shows a sudden growth trend, while the growth rate of knowledge tends to be stable under the sudden change state. Due to the great changes in the network structure of the industry-university-research cooperative innovation network, the role of general innovators and some advantageous innovators in knowledge innovation diffusion gradually declines, and hub advantage innovators play an important role in knowledge innovation diffusion ${ }^{[32]}$. It can be seen from Fig. 3 that the sudden change in the knowledge growth rate is constantly decreasing. Only when the hub advantage innovator is spreading knowledge innovation can the overall knowledge level of the network be greatly improved, and the overall knowledge level of the network presents a sudden growth trend. At this time, the overall knowledge level of the network shows a sudden growth trend, and the knowledge growth rate reaches the maximum value and tends to be stable at the time of mutation. 
In the process of knowledge innovation diffusion, the knowledge level of the innovators in the industry-university-research cooperative innovation network changes greatly, so that in the three stages of evolution, the knowledge level of the innovators changes too significantly under different degrees and different cooperation intensities, and it is difficult to determine the evolution law of the knowledge level of innovators directly in the corresponding graphs. Therefore, this paper intercepts $t=[1-100],[401-500]$ and [901,1000] from the three stages of evolution to reflect the changes in the knowledge level of the innovators under different degrees and different cooperation intensities.
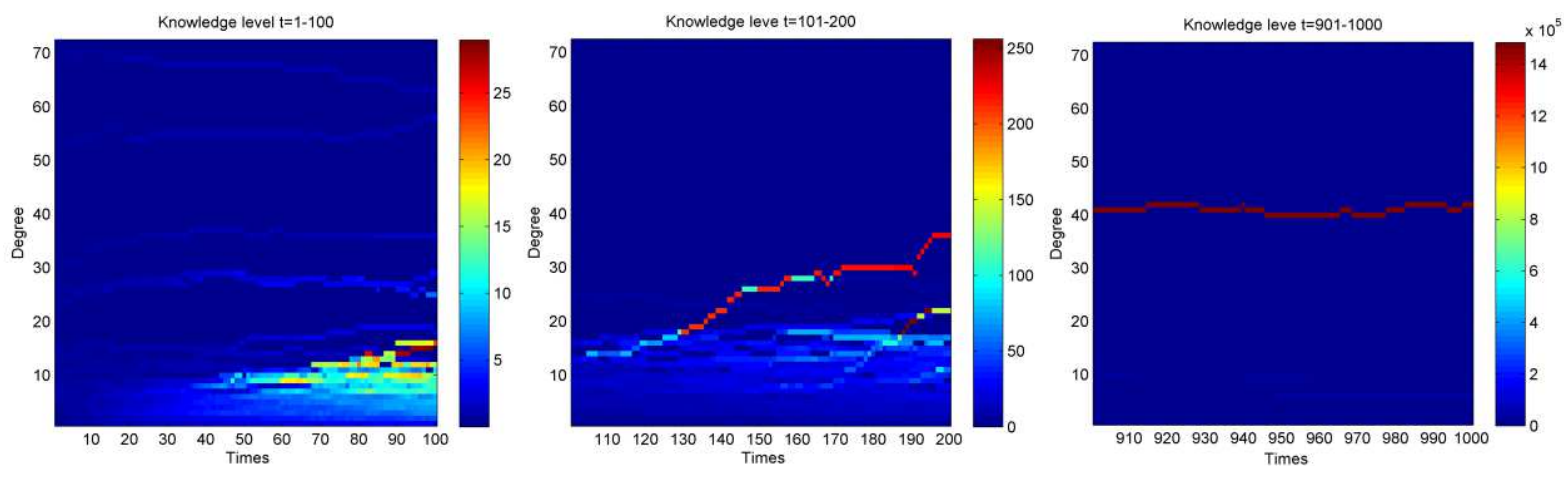

Figure 4. Changes in the knowledge level of innovators under different degrees in three periods

Fig. 4 shows the change in the knowledge level of the innovator under different degrees in three time periods. It can be seen from Fig. 4 that with the passage of time, the knowledge levels of the innovators with relatively large degree values increase significantly, and the larger the degree value is, the more significantly the knowledge level increases. This occurs because in the early stage of evolution $(t<100)$, the hub advantage innovator has a higher level of knowledge, but the knowledge levels of its neighbors are relatively low, which makes the knowledge that this kind of innovator can obtain relatively less knowledge through the diffusion process of knowledge innovation. Additionally, due to having a relatively small number of cooperative neighbors, a general innovator cannot acquire more knowledge in the process of knowledge innovation diffusion. In the middle and later stages of evolution $(t>400)$, the advantage of the cooperative relationships of advantage innovators is highlighted, which makes the knowledge acquired by such innovators through the process of knowledge innovation diffusion gradually increase, and the greater their degree values are, the higher the knowledge levels of the innovators are.
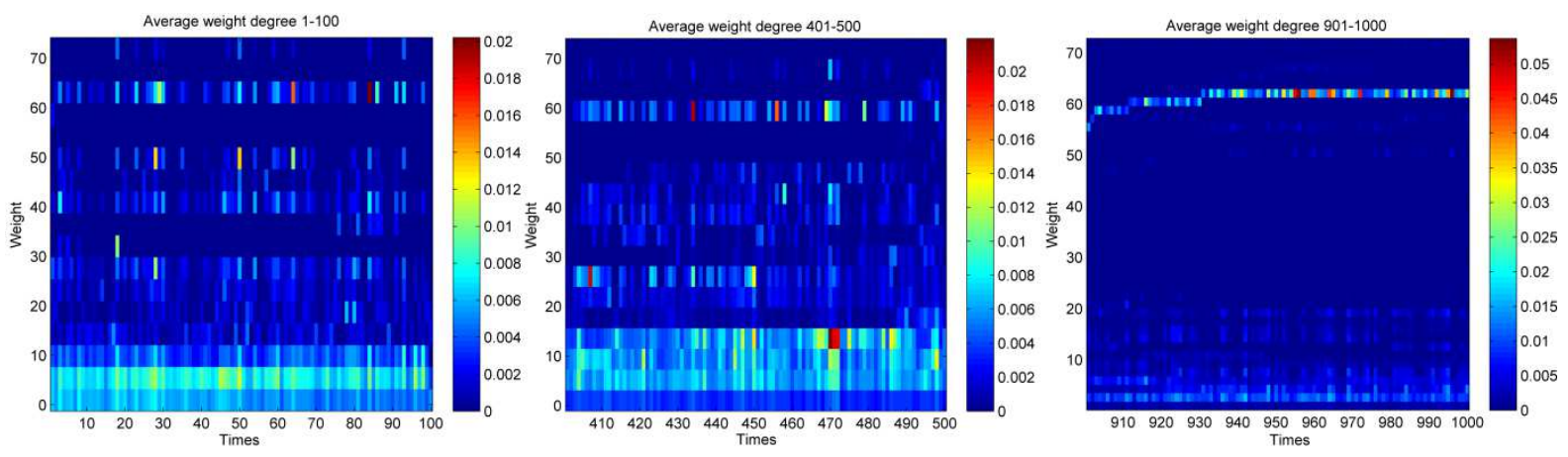

Figure 5. Changes in the knowledge levels of innovators under different cooperation intensities in three time periods

Fig. 5 shows the changes in the knowledge levels of the innovators under different cooperation intensities in three time periods. From Fig. 5, we can see that with the passage of time, the closer the cooperation is, the higher the level of knowledge diffusion among innovators. This occurs because in the early stage of evolution $(t<100)$, the number of innovators with relatively weak cooperative relationships 
in the network is relatively large, and in the process of knowledge innovation diffusion, the knowledge diffusion ability among these innovators is relatively high. In the middle and late stages of evolution $(t>400)$, the cooperation between innovators is more stable, and the knowledge increment that can be carried is gradually increased, so that the knowledge diffusion abilities among innovators with strong cooperative relationships are gradually increased, and the more stable the cooperative relationships are, the stronger the knowledge diffusion abilities among innovators are ${ }^{[33]}$.

\section{Change in uniformity of knowledge level distribution}

Fig. 6 shows the uniformity changes in the knowledge level distribution of the industry-university-research cooperative innovation network. It can be seen from Fig. 6 that the overall uniformity of the knowledge level distribution of the industry-university-research cooperative innovation network shows a trend of rapid growth and then tends to be stable, and with the advancement of time, there is a mutation point in the uniformity of the knowledge level. In the mid-term before evolution $(t<600)$, the uniformity of the knowledge level distribution in the industry-university-research cooperative innovation network shows a rapid growth trend, which shows that the knowledge level of the innovators in the network increases and differentiates and the degree of knowledge level differentiation between innovators is increasing. This occurs because under the interaction of network structure and knowledge innovation diffusion, with continuous change in the knowledge level of innovators, the network structure of the industry-university-research cooperative innovation network also changes. The change in the network structure reduces the scope of knowledge diffusion among innovators and restrains the efficiency of knowledge diffusion among them, so that the uniformity of the knowledge level distribution increases gradually $^{[34]}$. In the late stage of evolution $(t>600)$, the uniformity of the knowledge level distribution of the industry-university-research cooperative innovation network is maintained at a high level. The reason is that the network structure has been greatly changed, the scope of knowledge diffusion among innovators has been gradually reduced, and the degree of knowledge level differentiation among innovators has remained relatively stable, which ultimately tends to stabilize the uniformity of knowledge level distribution at a higher level ${ }^{[11]}$. In the whole evolution process, the uniformity of the knowledge level distribution of the industry-university-research cooperative innovation network always fluctuates. This occurs because on the one hand, the mutation point affects the knowledge differences between the innovators to a large extent when knowledge is spread through direct diffusion and indirect diffusion. On the other hand, the dynamic change in the structure of the industry-university-research cooperative innovation network has a different influence on the knowledge diffusion, which causes the uniformity of the knowledge level distribution of the innovators to fluctuate ${ }^{[18]}$.

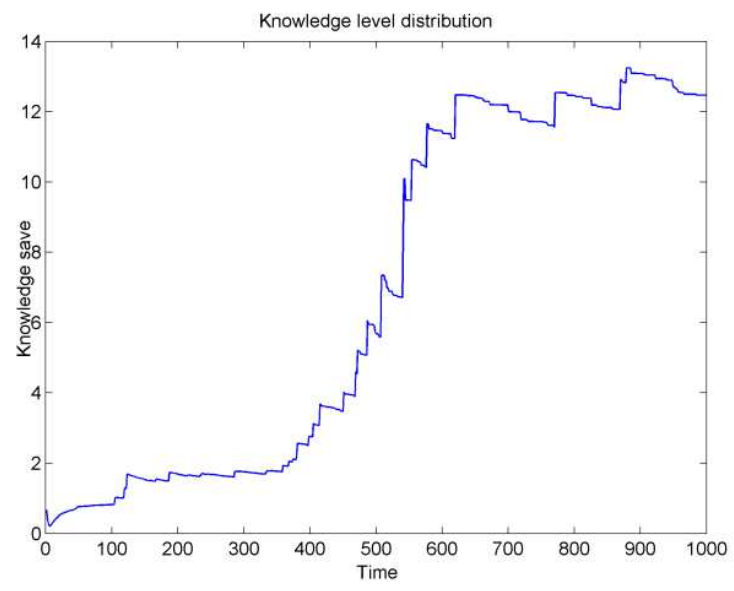

Figure 6. Uniformity of knowledge level

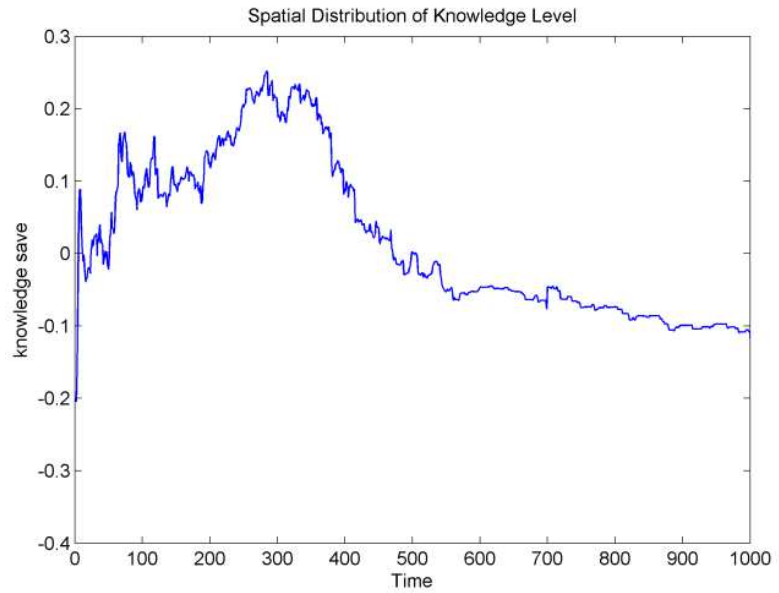

Figure 7. Spatial distribution of knowledge level in 
distribution in industry-university-research cooperative innovation network the cooperative innovation network of industry, university and research

\subsection{Spatial distribution of knowledge level}

Fig. 7 shows the change in the spatial distribution of the knowledge level of the industry-university-research cooperative innovation network. It can be seen from Fig. 7 that with the advancement of time, the spatial distribution of the knowledge level of the industry-university-research cooperative innovation network shows a trend of first increasing, then decreasing, and finally becoming stable.

In the early stage of evolution ( $t<300$ ), the overall spatial distribution of the knowledge level shows a steady upward trend, indicating that an increasing number of innovators with similar knowledge levels tend to form spatial agglomerations. In the middle of evolution $(300<t<600)$, the overall spatial distribution of the knowledge level shows a rapid downward trend, which shows that the spatial agglomeration formed by innovators with a similar knowledge level is disintegrating, while the innovators with large differences in knowledge level gradually form spatial agglomerations. In the later stage of evolution $(t>600)$, the spatial distribution of the knowledge level shows a stable trend, which shows that the spatial agglomeration formed by innovators with large differences in knowledge level tends to be stable. This occurs because in the early stage of evolution $(t<300)$, under the influence of the knowledge diffusion constraints and network structure, the innovators in the industry-university-research cooperative innovation network have a large scope of knowledge diffusion, which causes many innovators to have similar knowledge levels and form spatial agglomerations. With the promotion of time, under the interaction of the network structure and knowledge innovation diffusion, the network structure of the industry-university-research cooperative innovation network gradually changes, the network connectivity becomes weaker, and the distance between innovators gradually increases, so that the degree of knowledge level differentiation among innovators gradually increases, and the spatial agglomerations gradually change from the leading of innovators with similar knowledge levels to the leading of innovators with large knowledge level differences. Finally, in the late stage of evolution $(t>800)$, the influence of the network structure of the industry-university-research cooperative innovation network on knowledge diffusion tends to be stable, and under the influence of the constraints of knowledge diffusion, the innovators with large differences in knowledge level form spatial agglomerations. It can be seen that the constraints of the knowledge diffusion and network structure are the key factors in the process of knowledge innovation diffusion, determining the effective scope of knowledge diffusion and then affecting the spatial concentration of the knowledge levels of innovators in the industry-university-research cooperative innovation network.

\section{Dynamic evolution of individual knowledge level}

The change in the overall knowledge level of the network reveals the change rule for knowledge innovation diffusion on an overall level but cannot reflect the change in the knowledge level of each innovator. The dynamic evolution process of the individual knowledge levels is essentially the consistency and convergence of the changes in the knowledge levels of the innovators in the network ${ }^{[11]}$, which can reveal the evolution law of the individual knowledge levels well. Fig. 8 shows the change in the knowledge level of each innovator in the innovation network of industry-university-research cooperation in different periods. Among them, the abscissa represents the number of each innovator, and the ordinate represents the knowledge level of the innovator, including a total of 6 periods. The red node represents the enterprise, and the blue node represents the university-research institution. 

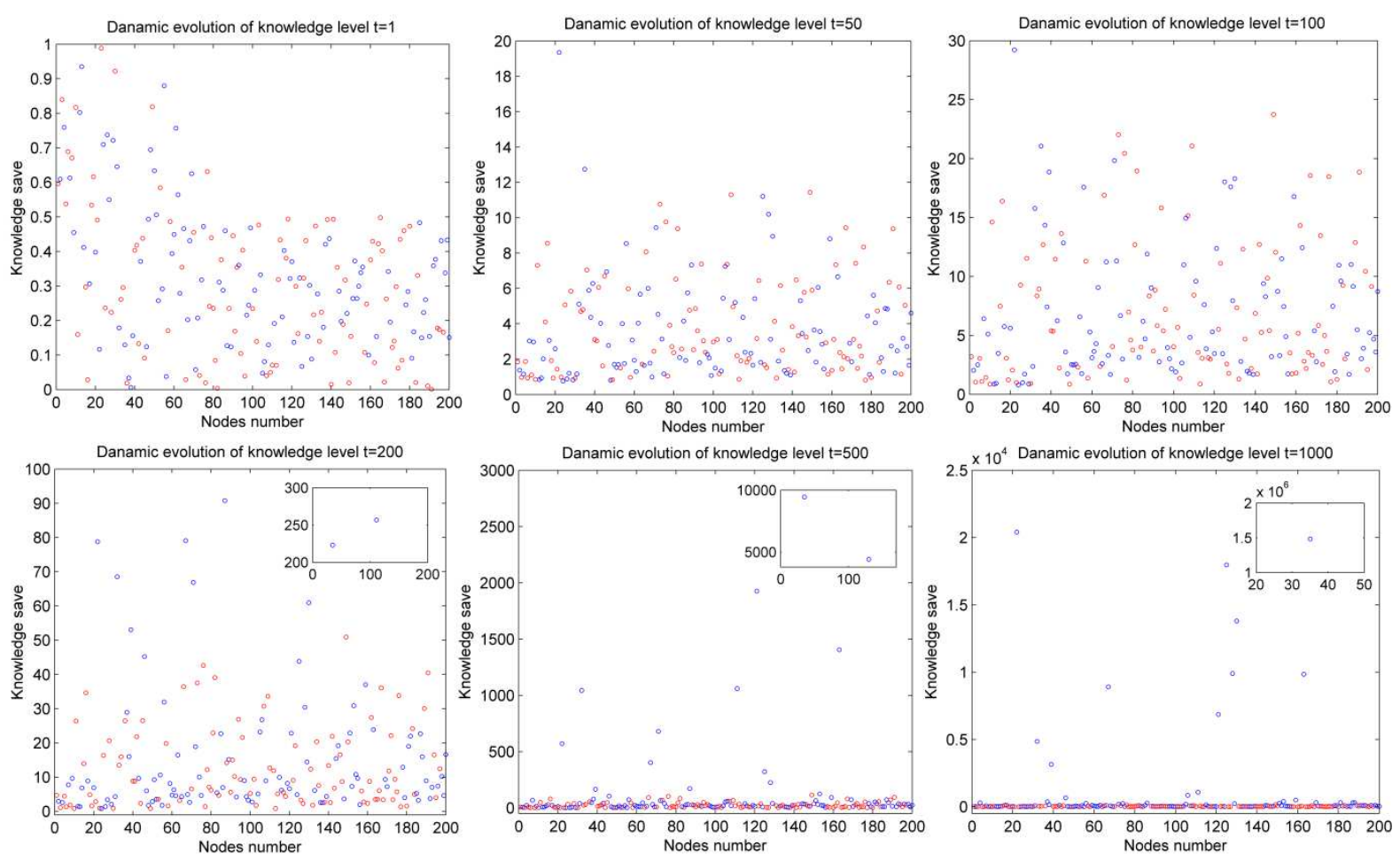

Figure 8. The changes in the knowledge levels of innovators in the industry-university-research cooperative innovation network in different periods

From Fig. 8, we can see that with the advancement of time, the knowledge levels of innovators in the industry-university-research cooperative innovation network present an obvious differential distribution, and the degree of differentiation is increasing. At the same time, the role of advantage university-research institutions in the diffusion process of knowledge innovation is becoming increasingly significant. At the initial moment (as shown in Fig. $8(t=1)$ ), the advantage innovators and the general innovators obey their respective uniform distributions. At the early stage of evolution (as shown in Fig. $8(t=50,100$ and $t=100)$ ), the degree of knowledge differentiation among innovators in the industry-university-research cooperative innovation network shows a trend of decreasing first and then increasing. This is because in the initial stage of evolution ( $t=50$ and $t=100$ ), the differentiation degree of knowledge level and the distance of the cooperation relationships between innovators in the industry-university-research cooperative innovation network are relatively small, and the scope of knowledge diffusion among innovators is relatively large, so that knowledge can achieve global diffusion in the network and make the differentiation degree of knowledge level between innovators relatively small. When the network evolves to a certain period $(t=200)$, the structure of the industry-university-research cooperative innovation network changes to a certain extent, the network connectivity decreases gradually, and the scope of knowledge diffusion increases gradually, so that the degree of knowledge level differentiation among innovators in the network increases slowly. In the middle and later stages of evolution (as shown in Fig. 8 $(t=500$ and $t=1000)$ ), the degree of knowledge level differentiation among innovators in the industry-university-research cooperative innovation network gradually increases, and the role of university-research institutions in the diffusion process of knowledge innovation is prominent.

This occurs because with increasing knowledge level differentiation and cooperative distance between innovators, the scope of knowledge diffusion among innovators decreases rapidly, and the efficiency of the knowledge diffusion among innovators in the network decreases ${ }^{[35]}$. This makes it difficult for innovators to realize effective diffusion of knowledge, so that the hub advantage innovators in the network have high 
levels of knowledge, while the knowledge levels of other innovators are relatively low, leading to an increasing degree of knowledge level differentiation among innovators. In addition, in the industry-university-research cooperative innovation network, due to the relatively strong knowledge innovation ability of advantage university-research institutions, with the advancement of time, the knowledge level difference between hub university-research institutions and other innovators gradually increases, and the role of hubs in knowledge innovation diffusion is increasingly prominent.

\section{Conclusions}

Based on the interaction between the network structure and knowledge innovation diffusion, this paper constructs the corresponding diffusion model of knowledge innovation and uses complex network theory and simulation analysis methods to explore the evolution law of knowledge innovation diffusion in the industry-university-research cooperative innovation network. The results show that (1) the overall knowledge level of the network shows a trend of slow growth followed by abrupt growth, while the growth rate of knowledge shows a trend of slow growth followed by abrupt growth followed by stable growth. (2) The larger the degree value of the innovator is, the more significant the increase in the knowledge level is; the more stable the cooperative relationship between innovators is, the higher the level of knowledge diffusion is. (3) The uniformity of the knowledge level distribution shows a trend of rapid growth and then tends to be stable. There are mutation points in the process of knowledge level uniformity change, and the dynamic changes in the knowledge diffusion mode and network structure are the reasons for the emergence of mutation points in the network. (4) The spatial distribution of the knowledge level shows a trend of first increasing, then decreasing, and finally becoming stable. The constraints of knowledge diffusion and network structure are the key to knowledge innovation diffusion, which greatly affects the spatial concentration of the knowledge level of innovators. (5) The different degrees of knowledge between innovators increase gradually, and the different degrees of innovator scale decrease gradually. In this paper, based on the two aspects of knowledge innovation and knowledge diffusion, we comprehensively consider the influencing factors of the knowledge innovation diffusion process, such as the heterogeneity of the innovator and the strength of the cooperative relationship, as well as the interaction between network structure and knowledge innovation diffusion, and establish the corresponding knowledge innovation diffusion model, but only analyze the evolutionary rule of knowledge innovation diffusion under the industry-university-research cooperative innovation network established by the weighted evolution BBV model. Future research can introduce other weighted networks or real networks for comparative analysis and analyze the coevolution rule of knowledge innovation diffusion under different weighted networks.

\section{Acknowledgments}

We acknowledge the financial support provided by the National Natural Science Foundation of China (Grant No. 71473055) and Harbin Engineering University Scholarship Fund.

\section{References}

1. Liu, M., Ma, Y., Liu, Z. \& You, X. An Iur Evolutionary Game Model On the Patent Cooperate of Shandong China. Physica A: Statistical Mechanics and its Applications. 475, 11-23 (2017).

2. Fukugawa, N. Knowledge Spillover From University Research Before the National Innovation System

Reform in Japan: Localisation, Mechanisms, and Intermediaries. Asian Journal of Technology Innovation. $1-23$ (2016).

3. Jian-Guo, L., Guang-Yong, Y. \& Zhao-Long, H. A Knowledge Generation Model Via the Hypernetwork. 
Plos One. 9, e89746 (2014).

4. Cowan, R. \& Jonard, N. Knowledge Creation, Knowledge Diffusion and Network Structure. Lecture Notes in Economics \& Mathematical Systems. 503, 327-343 (2001).

5. Wang W P, Zhang B. Emergence characteristics of knowledge flow in knowledge networks under dynamic relationship strengths. Journal of Management Sciences in China. 16, 1-11 (2013).

6. Chen W, Li C Y, Zhou W, et al. Research on the weighted patent cooperation network based on new energy vehicles. Journal of the China Society for Scientific and Technical Information. 35, 563-572 (2016).

7. Barrat, A., Barthélemy, M. \& Vespignani, A. Weighted Evolving Networks: Coupling Topology and Weight Dynamics. Phys. Rev. Lett. 92, 228701 (2004).

8. Wadhwa, C. P. R. H. Knowledge, Networks, and Knowledge Networks. Journal of Management. 38, 1115-1166 (2012).

9. Xie, X., Fang, L. \& Zeng, S. Collaborative Innovation Network and Knowledge Transfer Performance: A Fsqca Approach. Journal of Business Research. 69, 5210-5215 (2016).

10. Darvish, H. \& Tonta, Y. Diffusion of Nanotechnology Knowledge in Turkey and its Network Structure. Scientometrics. 107, 569-592 (2016).

11. Zhou W, Chen W, Lang Y F. Knowledge dynamic growth in the innovation network of industrial cluster: Based on process perspective. Journal of System Engineering. 30, 431-441 (2015).

12. Mao Y L, Wang F. Spatial Correlation in Evolution of Regional Comparative Advantages: Evidence on the Impact of Knowledge Diffusion. China Industrial Economics. 11, 136-154 (2018).

13. Havakhor, T., Soror, A. A. \& Sabherwal, R. Diffusion of Knowledge in Social Media Networks: Effects of Reputation Mechanisms and Distribution of Knowledge Roles: Diffusion of Knowledge in Social Media Networks. Information Systems Journal. 28, 104-141 (2018).

14. Cowan, R. \& Jonard, N. Network Structure and the Diffusion of Knowledge. Journal of Economic Dynamics and Control. 28, 1557-1575 (2004).

15. Wang, X. Forming Mechanisms and Structures of a Knowledge Transfer Network: Theoretical and Simulation Research. Journal of Knowledge Management. 17, 278-289 (2013).

16. Zheng, W., Pan, H. \& Sun, C. A Friendship-Based Altruistic Incentive Knowledge Diffusion Model in Social Networks. Information Science. 491, 138-150 (2019).

17. Huang W Q, Zhuang X T, Yao S. Study on Knowledge Diffusion of Industry Clusters Based on the Innovation Cooperation Network. Journal of Management Science. 2, 13-23 (2012).

18. Zhou W, Chen W, Lang Y F. Modeling and Simulation Analysis of Process of Knowledge Innovation and Diffusion Based on Industry Cluster Innovation Network. Operations Research and Management Science. 6, 257-265 (2014).

19. Zhang, L., Wei, Q., Yuan, Y. \& Li, Y. Knowledge Diffusion Simulation of Knowledge Networks: Based On Complex Network Evolutionary Algorithms. Cluster Computing. 1-11 (2018).

20. Yu X Y, Zeng D M, Chen Y L, et al. Modeling and simulation of the knowledge increase process in the technology innovation network. Science Research Management. 10, 35-41(2013).

21. Luo, S., Du, Y., Liu, P., Xuan, Z. \& Wang, Y. A Study On Coevolutionary Dynamics of Knowledge Diffusion and Social Network Structure. Expert Syst. Appl. 42, 3619-3633 (2015).

22. Tur, E. M. \& Azagra-Caro, J. M. The Coevolution of Endogenous Knowledge Networks and Knowledge Creation. Journal of Economic Behavior \& Organization. 145, 424-434 (2018).

23. Gross, T. \& Blasius, B. Adaptive Coevolutionary Networks: A Review. J.r.soc.interface. 5, 259 (2008).

24. Hemphälä, J. \& Magnusson, M. Networks for Innovation - but What Networks and What Innovation? Creativity \& Innovation Management. 21, 3-16 (2012). 
25. Arne, T. \& Nowak, M. A. Evolution of Cooperation by Multilevel Selection. P. Natl. Acad. Sci. Usa. 103, 10952-10955 (2006).

26. LI, J. \& CHANG, X. The Influence Factors of Knowledge Transfer: A Meta-Analytic Review. Studies in Science of Science. 3, 394-406 (2013).

27. Luo, S., Du, Y., Peng, L., Xuan, Z. \& Wang, Y. A Study On Coevolutionary Dynamics of Knowledge Diffusion and Social Network Structure. Expert Syst. Appl. 42, 3619-3633 (2015).

28. Yang, G., Hu, Z. \& Liu, J. Knowledge Diffusion in the Collaboration Hypernetwork. Physica A: Statistical Mechanics and its Applications. 419, 429-436 (2015).

29. Konno, T. Knowledge Spillover Processes as Complex Networks. Physica A Statistical Mechanics \& Its Applications. 462, 1207-1214 (2016).

30. Liu, J. G. et al. Knowledge Diffusion of Dynamical Network in Terms of Interaction Frequency. Sci. Rep.-Uk. 7, 10755 (2017).

31. Lin, M. \& Li, N. Scale-Free Network Provides an Optimal Pattern for Knowledge Transfer. Physica A Statistical Mechanics \& Its Applications. 389, 473-480 (2012).

32. Jian, W. Knowledge Creation in Collaboration Networks: Effects of Tie Configuration. Research Policy. 45, 68-80 (2016).

33. Lakpetch, P. \& Lorsuwannarat, T. Knowledge Transfer Effectiveness of University - Industry Alliances. International Journal of Organizational Analysis. 20, 128-186 (2012).

34. Fritsch, M. \& Kauffeld-Monz, M. The Impact of Network Structure On Knowledge Transfer: An Application of Social Network Analysis in the Context of Regional Innovation Networks. Annals of Regional Science. 44, 21 (2010).

35. Mueller, M., Bogner, K., Buchmann, T. \& Kudic, M. The Effect of Structural Disparities On Knowledge Diffusion in Networks: An Agent-Based Simulation Model. Journal of Economic Interaction \& Coordination. 12, 1-22 (2016). 


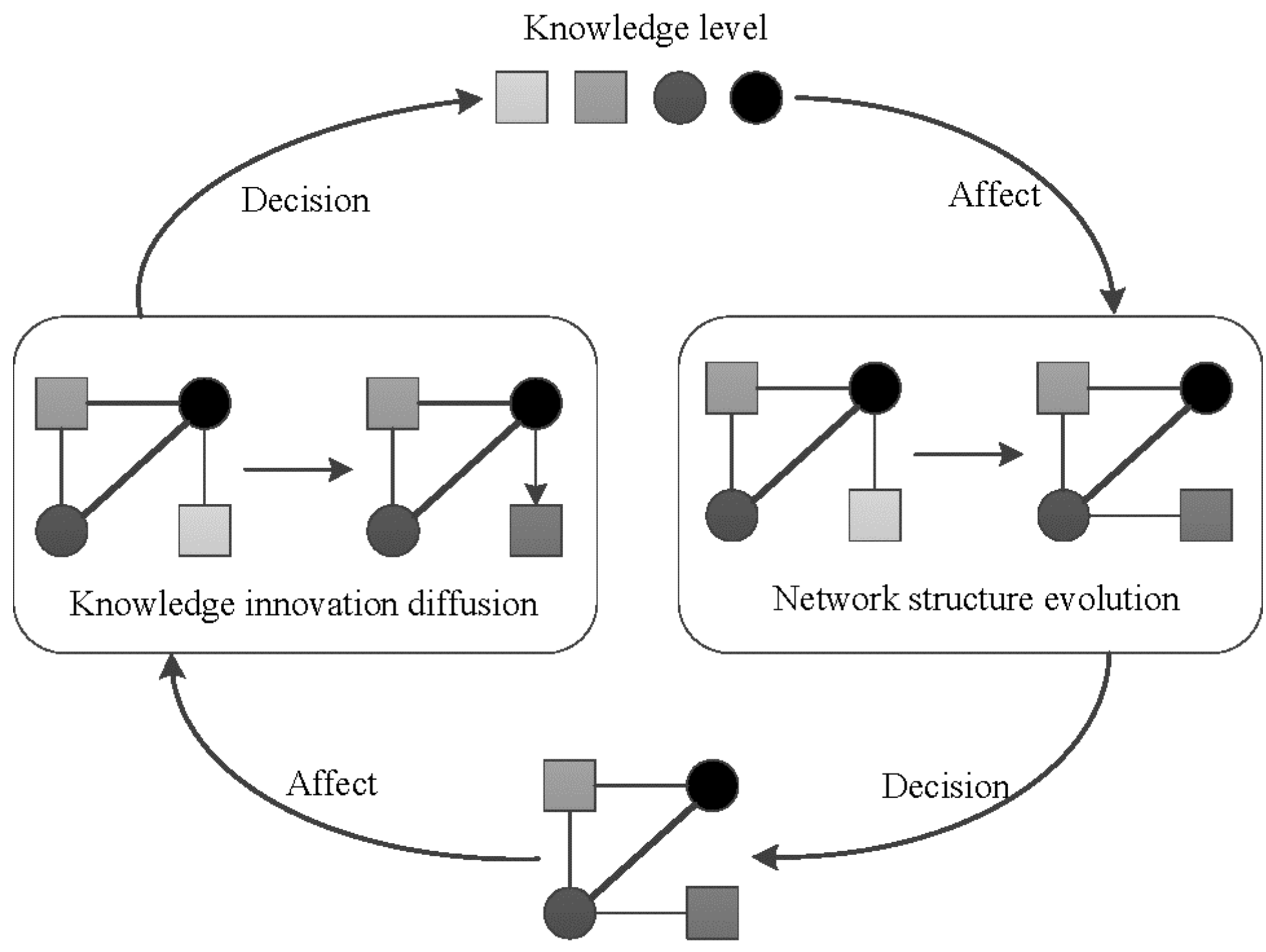

Network structure

Figure 1

Analysis framework of interaction process between industry-university-research cooperative innovation network structure and knowledge innovation diffusion 


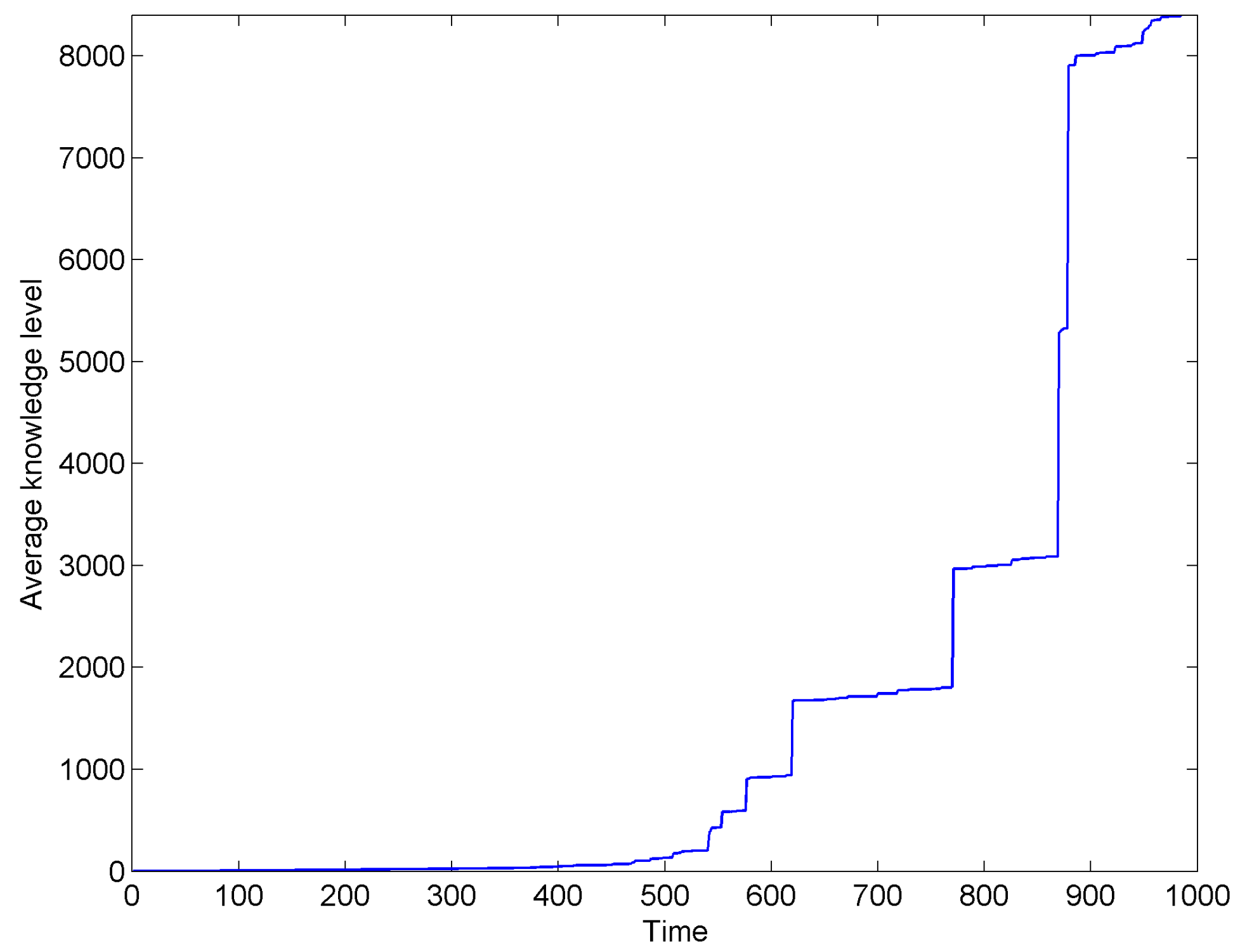

Figure 2

Changes in the overall knowledge level of the network 


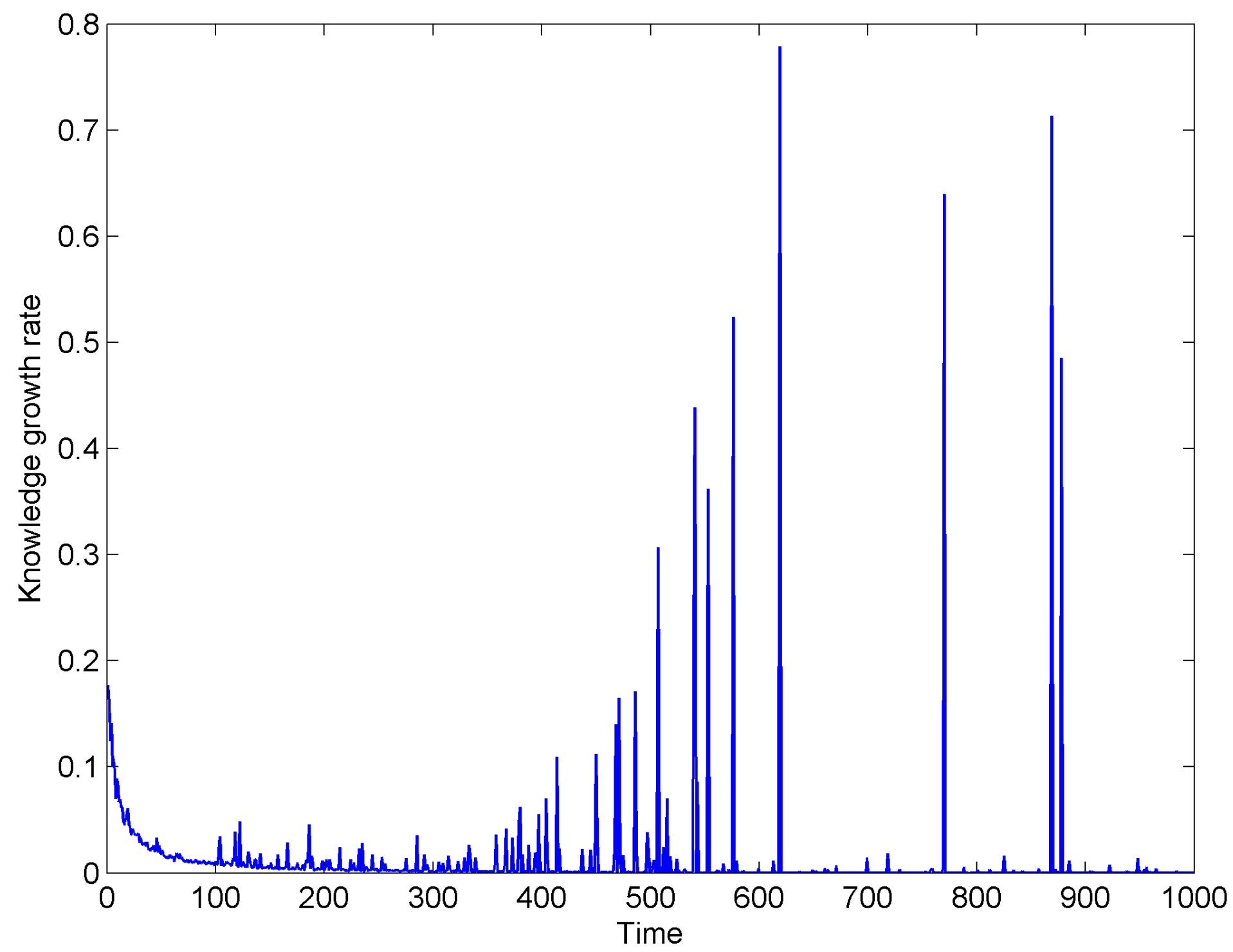

Figure 3

Change in the knowledge growth rate
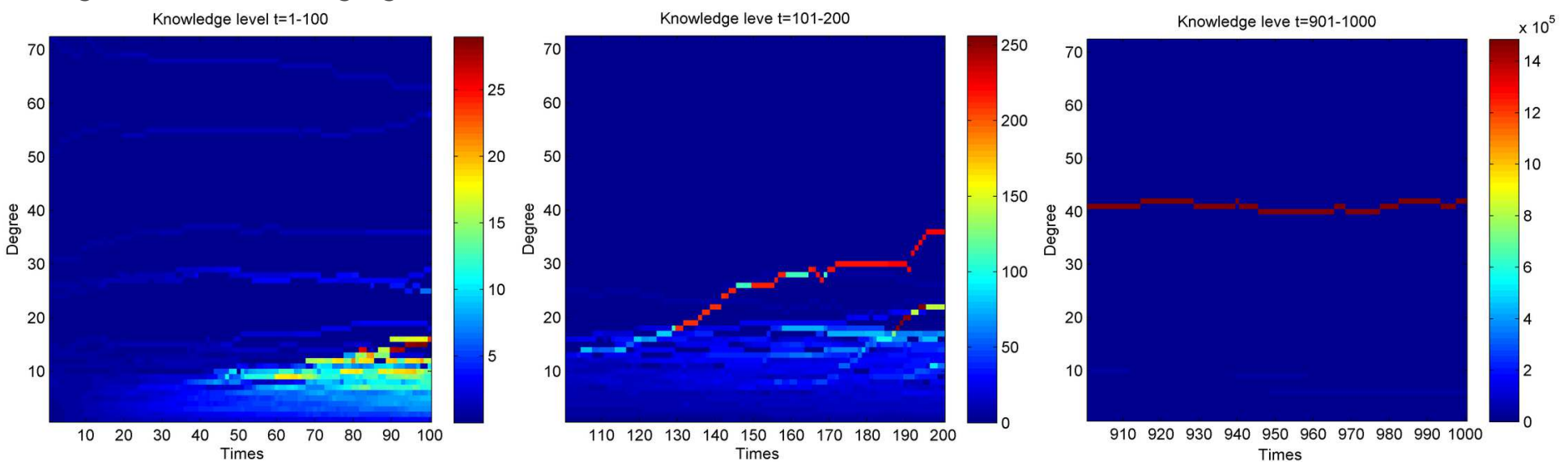

Figure 4 
Changes in the knowledge level of innovators under different degrees in three periods
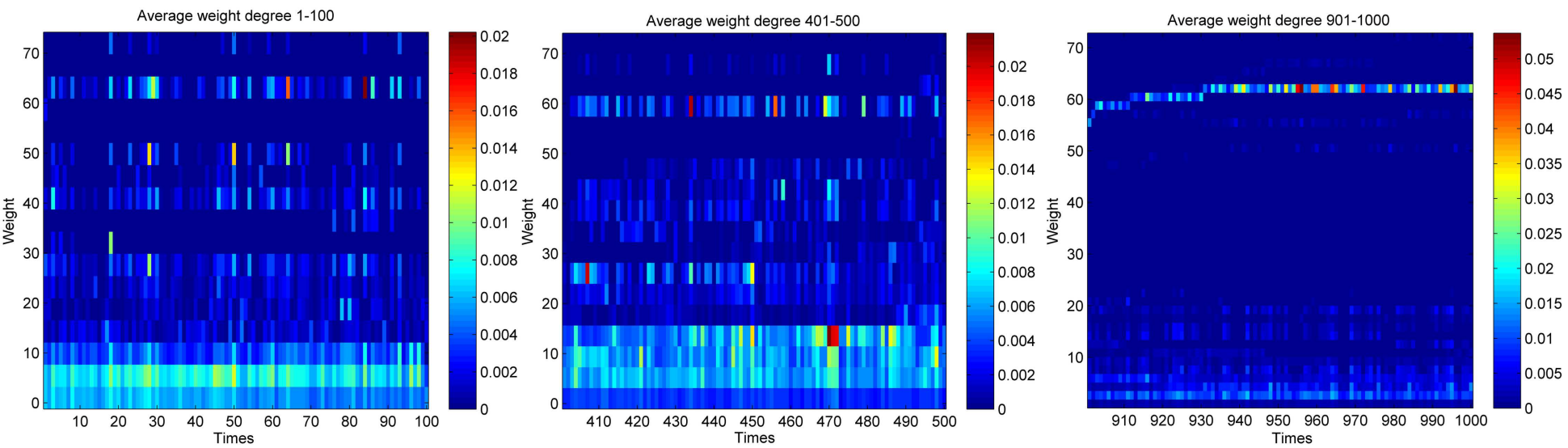

Figure 5

Changes in the knowledge levels of innovators under different cooperation intensities in three time periods

Knowledge level distribution

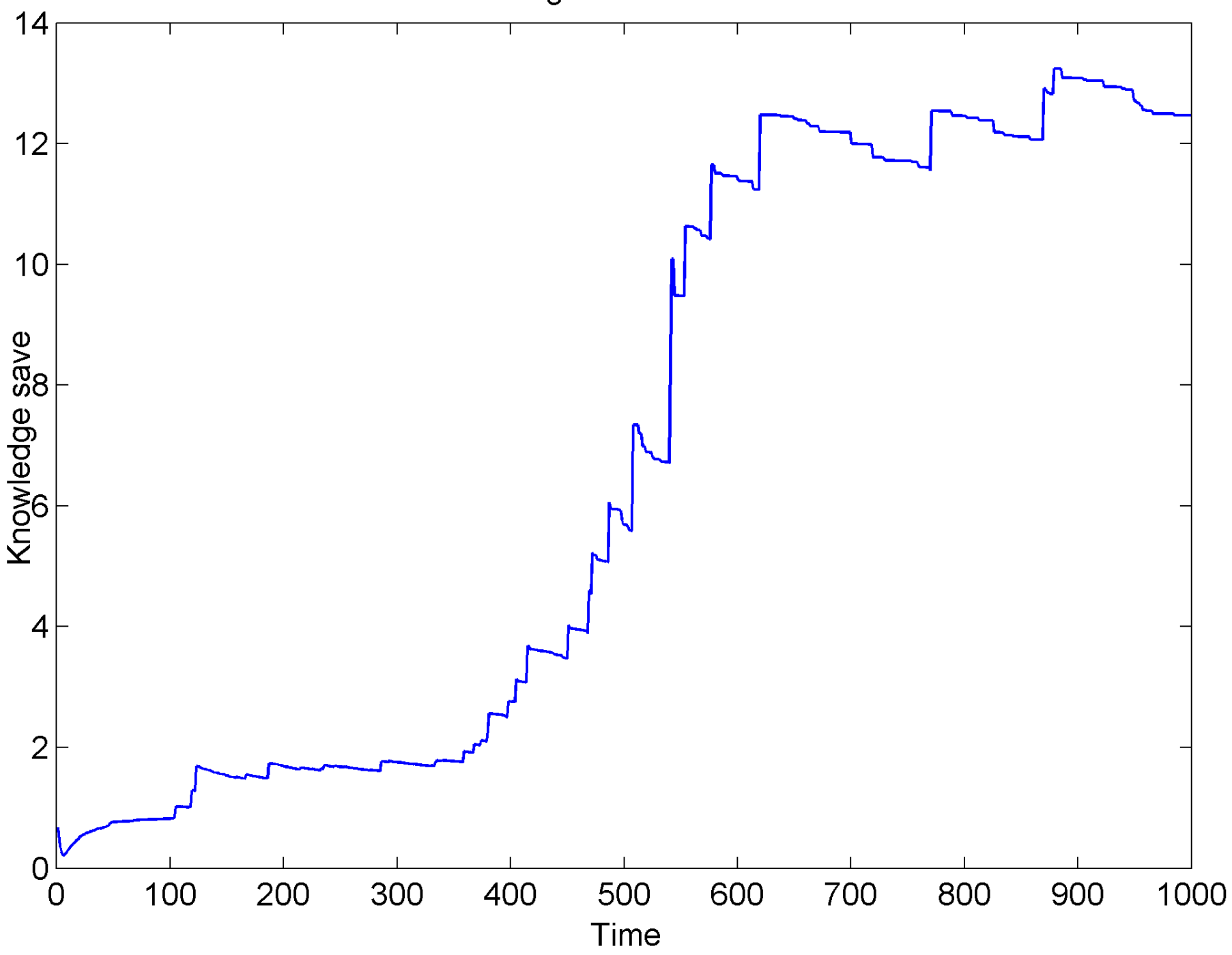

Figure 6 
Uniformity of knowledge level distribution in industry-university-research cooperative innovation network Spatial Distribution of Knowledge Level

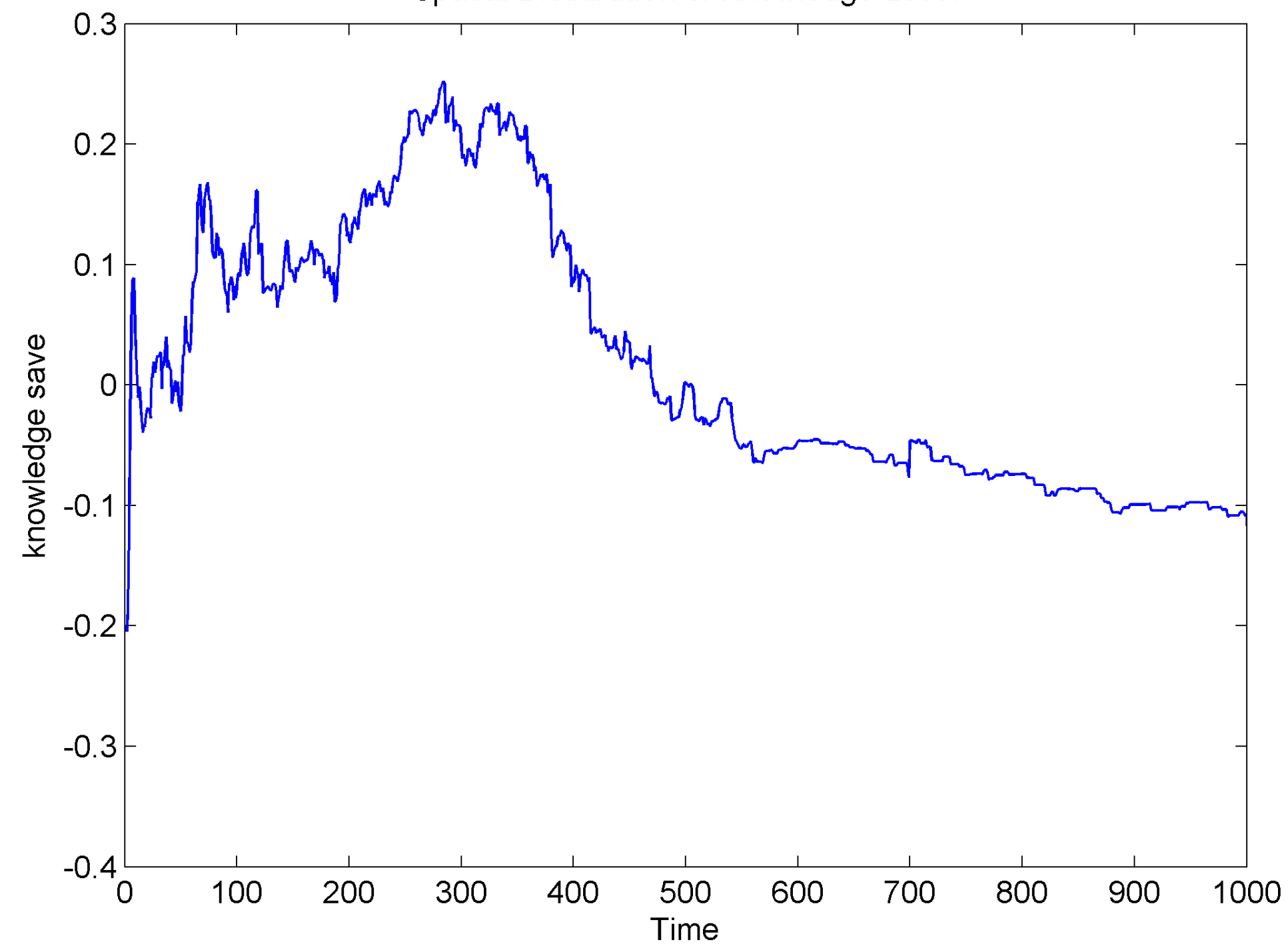

Figure 7

Spatial distribution of knowledge level in the cooperative innovation network of industry, university and research 

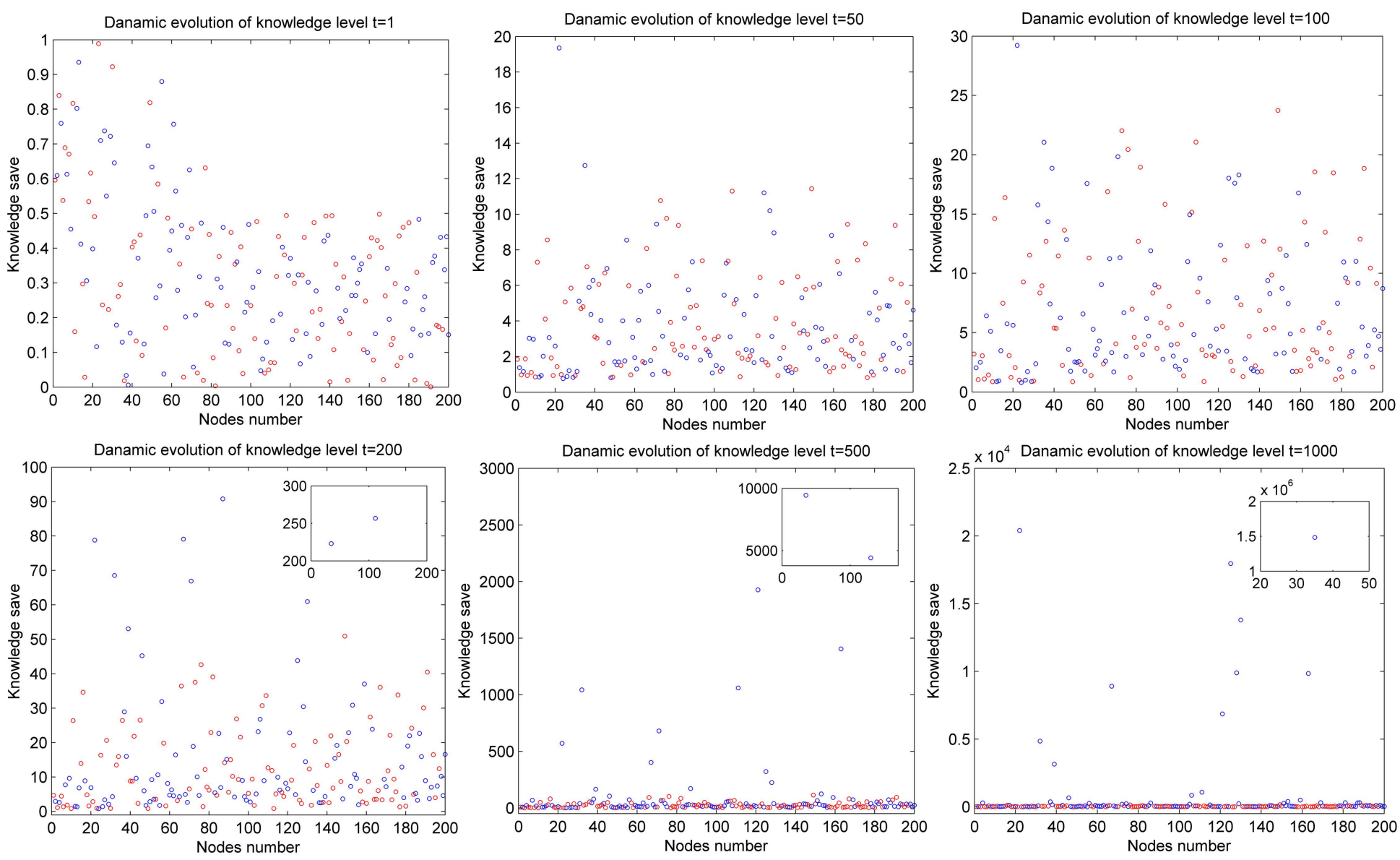

Figure 8

The changes in the knowledge levels of innovators in the industry-university-research cooperative innovation network in different periods

\section{Supplementary Files}

This is a list of supplementary files associated with this preprint. Click to download.

- Originalnetworkdata.zip 